\title{
Microstructures of glassy alloys: presence of hills, valleys, and veins
}

\author{
T.A.M. ABOKI \\ GMS-LPCS UMR 7045, Chimie Paristech, 75231 Paris Cedex 05, France
}

\begin{abstract}
Amorphous ribbon surfaces, wheel and free sides are peculiar, but no microstructural description is not yet proposed. Here, we introduce a new description of the two surfaces by analogy with biological organs like a leaf as a network of hills, valleys, and veins. The venation can help understand the transport properties like heat dissipation during ribbon processing and mechanical properties like resilience or tensile strength of the amorphous ribbon. The new microstructure presentation can be useful to describe the crystallization of glassy materials.
\end{abstract}

\section{Introduction}

Most of metallic glassy alloys are processed via liquid quenching. One of the characteristics of the solid material prior to the verification of the glassiness is the lustrous aspect of both the free side and the wheel side surfaces. These faces of the ribbon sometimes exhibit slight different microstructures showed by X-rays diffraction [1]. The feature of the wheel-side surface is dependent of the wheel's material chemical composition [2,3] and the surface's roughness. However, few interests were paid to the morphologies of these two surfaces.

Here, we present the microstructures of the free side surface (FSS) and the wheel side surface (WSS) of some amorphous ribbons, which we compare to those of bulk glassy metallic material and also to that of glass-forming alloys. We found some common features between these microstructures that can be grouped as hills, valleys, and veins. The latter are usually observed for fracture surface, which is a clue for liquid flow path. These common features are similar to a leaf and can be useful to describe the amorphous/glassy microstructure and the related transport and mechanical properties as well as the distribution of crystalline phases in annealed glassy material.

\section{Experimental}

Ribbons and bulk glassy materials (BMG) are processed respectively by melt spinning and injection casting. Observations are performed by means of an Olympus optical microscope, Hitachi S-2500 scanning electron microscope (SEM), and Jeol JEM FX-2000 transmission electron microscope (TEM). Ribbons are annealed under vacuum at different temperatures during 18 hours.

\section{Results and discussions}

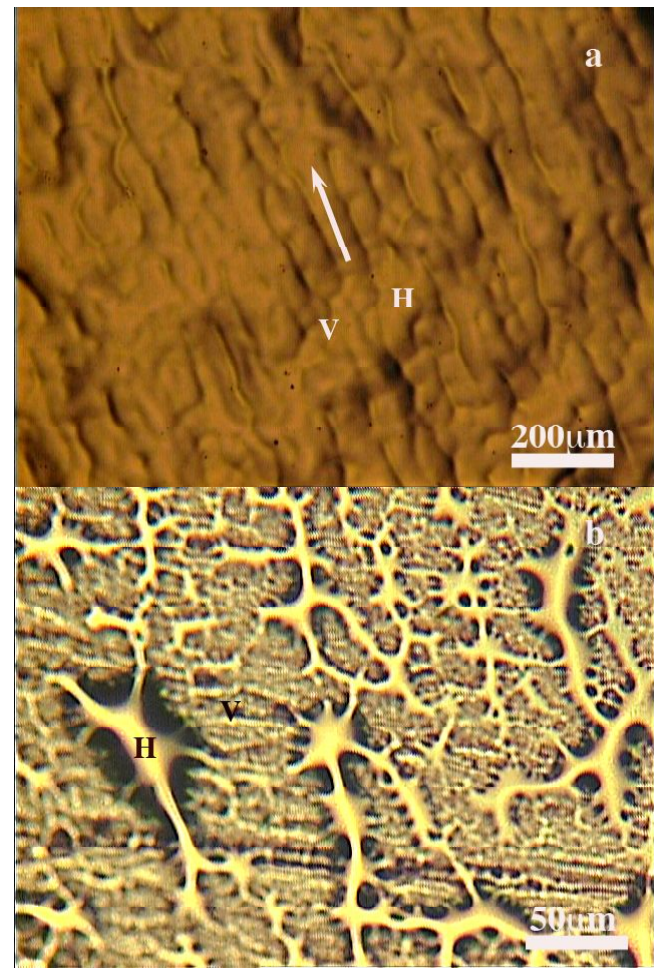

Fig. 1. Optical micrographs of free-side and wheel-side surfaces of as-cast $\mathrm{Fe}_{81} \mathrm{~B}_{13.5} \mathrm{Si}_{3.5} \mathrm{C}_{2}$ ribbon.

Fig. 1 shows the optical micrographs of FSS (a) and WSS (b) microstructures of the as-cast $\mathrm{Fe}_{81} \mathrm{~B}_{13,5} \mathrm{Si}_{3,5} \mathrm{C}_{2}$ ribbon. Both surfaces' morphologies, typical of ribbons processed by melt spinning, indicate the relief as ' raised map' surfaces. The FSS (Fig. 1a) shows a lamellar 
microstructure with lamella of about $30 \mu \mathrm{m}$ in width and 200-300 $\mu \mathrm{m}$ in length and their interconnection forming a hill and valley network. The smaller lamellae larger than $6 \mu \mathrm{m}$ are named veins and located in the valleys (V). The hills are the connection of multiple lamellae. Their distribution in the microstructure is about 280-400 grains/ $\mathrm{mm}^{2}$. Their mean width is about 40-60 $\mu \mathrm{m}$. The microstructure is textured in the ribbon ejection direction, and the mean intervals between veins are about $2 \mu \mathrm{m}$ with a maximum width of $40 \mu \mathrm{m}$, the minimum being about $500 \mathrm{~nm}$. The WSS displays irregular n-fold ( $\mathrm{n}$ from 3 to 6) grains like beads, connected by various sized lamellae respectively named hills $(\mathrm{H})$ and veins through the valleys (V) (Fig. 1b). The whole surface shows a leaflike or a web-like wing of some insects' morphology. The biggest hills' distribution within this microstructure is about 260-300 grains $/ \mathrm{mm}^{2}$ and their mean diameter is about $60 \mu \mathrm{m}$. However, the mean diameter of the smaller hills is about few micrometers, even nanometer. In all cases, the morphology of the surfaces is dependent of the casting conditions and the composition of the alloy. By analogy, the two surfaces are similar to upper and to lower surfaces of a leaf that are considered as natural network associated to transport system and mechanical resilience [4-6]. The same description can be associated to the ribbon microstructures for instance the transport properties during the solidification of the melt and resilience in the solid state. The peculiarity of the mechanical properties of amorphous/glassy materials can be associated with the presence of such a network. For instance, the hardness of the $\mathrm{Zr}_{57} \mathrm{Cu}_{20} \mathrm{Al}_{7.5} \mathrm{Ni}_{10}$ ribbon, about $460 \mathrm{Hv}$, is identical both in the valley of the WSS and on FSS (Fig. 2). The hardness value is also similar to that of bulk $\mathrm{Zr}_{57} \mathrm{Cu}_{20} \mathrm{Al}_{7.5} \mathrm{Ni}_{10} \mathrm{Ti}_{5}$ glass, where ripples are observed on ingot surface.

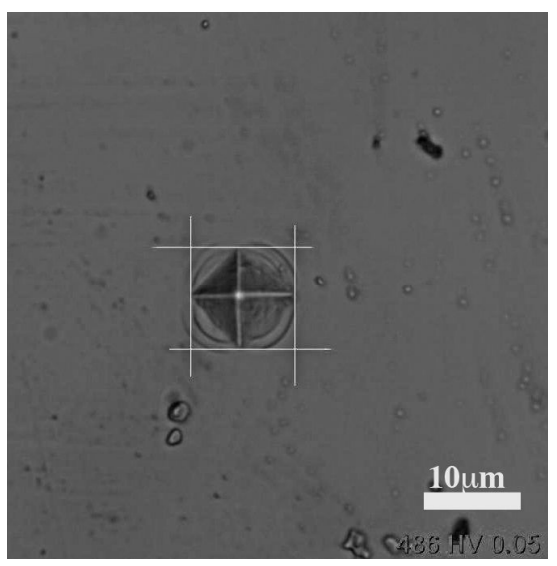

Fig. 2. Hardness indentation on $\mathrm{Zr}_{57} \mathrm{Cu}_{20} \mathrm{Al}_{7.5} \mathrm{Ni}_{10}$ amorphous ribbon FSS.

Figs. 3 and 4 show the optical and SEM micrographs respectively of $\mathrm{Fe}_{81} \mathrm{~B}_{13.5} \mathrm{Si}_{3.5} \mathrm{C}_{2}$ and $\mathrm{Fe}_{40} \mathrm{Ni}_{38} \mathrm{Mo}_{4} \mathrm{~B}_{18}$ amorphous ribbons annealed at $750^{\circ} \mathrm{C}$ during $18 \mathrm{H}$. The annealing treatment does not change the microstructure in

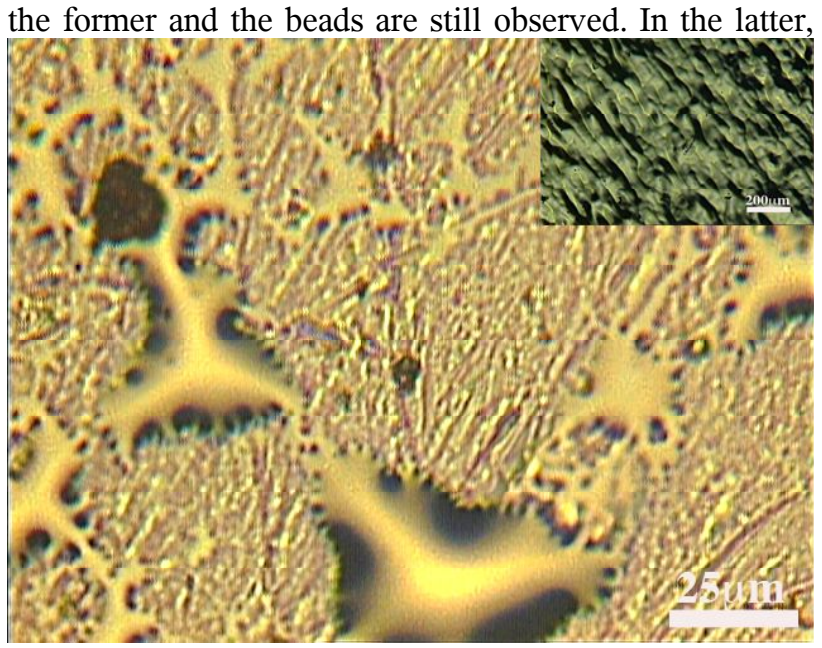

Fig. 3. Optical micrographs of free (inset) and wheel faces of $\mathrm{Fe}_{81} \mathrm{~B}_{13.5} \mathrm{Si}_{3.5} \mathrm{C}_{2}$ ribbon after annealing at $750^{\circ} \mathrm{C}$ during $18 \mathrm{~h}$ in vacuum.

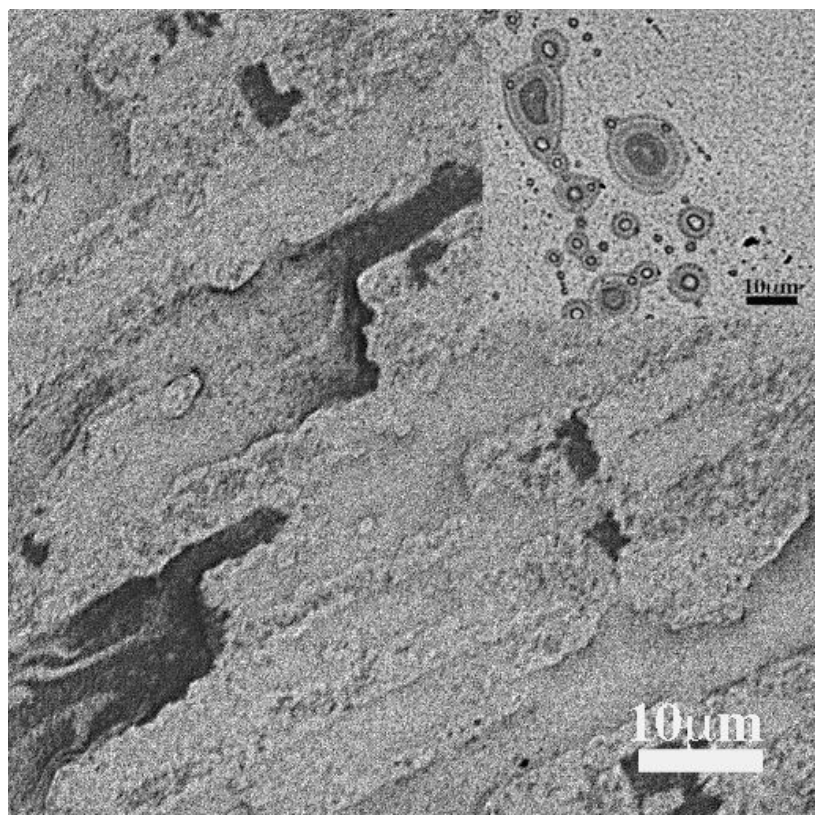

Fig. 4. SEM micrographs of free (inset) and wheel faces of $\mathrm{Fe}_{40} \mathrm{Ni}_{38} \mathrm{Mo}_{4} \mathrm{~B}_{18}$ ribbon after annealing at $750^{\circ} \mathrm{C}$ during $18 \mathrm{H}$ in vacuum.

the $\mathrm{Fe}_{40} \mathrm{Ni}_{38} \mathrm{Mo}_{4} \mathrm{~B}_{18}$ alloy, the annealing temperature is beyond the first $\left(405^{\circ} \mathrm{C}\right)$ and the second crystallization $\left(570^{\circ} \mathrm{C}\right)$ stages. The morphology of hills, the beads, on WSS is similar to that observed in Fig.1, already described in a glass-forming alloy [7]. Again, the annealing does not affect the morphology of the two surfaces. However, pitting appears on the FSS within the typical 'orange skin' glassy [8] microstructure (inset Fig. 4). The observation indicates that no large diffusion occurs at $750^{\circ} \mathrm{C}$ that seems to be confirmed by the TEM microstructure of glass-forming alloy. In the latter, the electrochemical thinning of the specimen for TEM observations preferentially conserved the hills and the valleys (Fig. 5). Details as twins, plate-like crystals are also observed with arrow's head that can be compared to the serrated edge of a leaf. Particularly, the small veins that connect the hills to the valleys are identical in Figs. 1,3 , and 4 . 


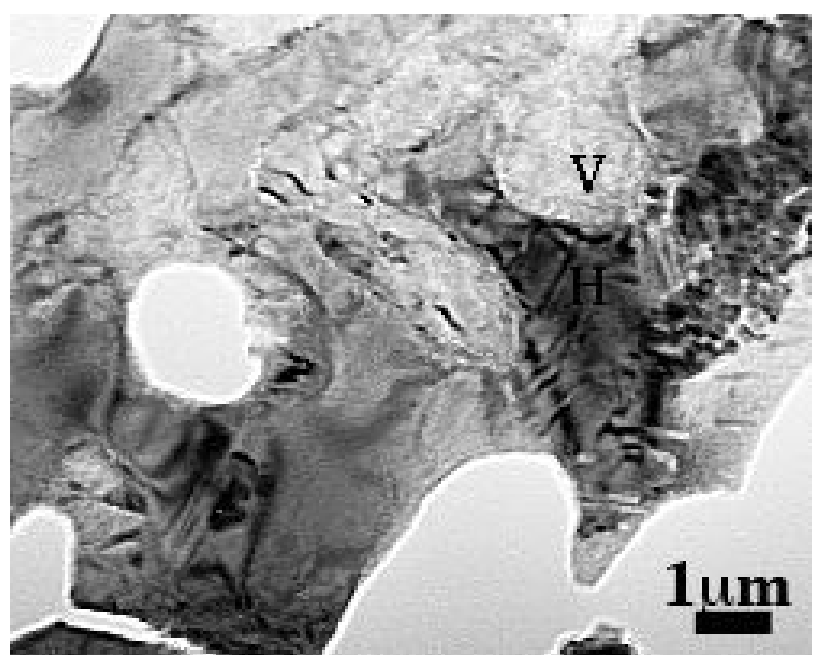

Fig. 5. TEM bright field image of a glass-forming $\mathrm{Zr}_{65} \mathrm{Cu}_{20} \mathrm{Al}_{10} \mathrm{Ni}_{10}$ alloy.

After crystallization, ribbons become usually brittle. The rupture of the $\mathrm{Fe}_{40} \mathrm{Ni}_{38} \mathrm{Mo}_{4} \mathrm{~B}_{18}$ ribbon annealed at $750^{\circ} \mathrm{C}$ during $18 \mathrm{H}$ is different in the valley and in the hill along the rupture's line in Fig. 6. The rupture's line is straight and serrated respectively on the hill and in the valley probably due to the distribution of plate-like crystallite (see black arrow inset figure). Can the drastic decrease of the resistivity, for instance, of $\mathrm{Fe}_{40} \mathrm{Ni}_{38} \mathrm{Mo}_{4} \mathrm{~B}_{18}$ ribbon from 160 to $60 \mu \Omega$.cm after heat treatment [9] be connected to the ribbon's brittleness? It is likely that the suggested new description of the amorphous ribbon microstructure is suitable for mechanical properties understanding. Moreover, the network of hills, valleys, and veins introduction can explain the continuous flow of the melt during the solidification (length of the ribbon), the discontinuous flow leading to blend amorphouscrystalline needles.

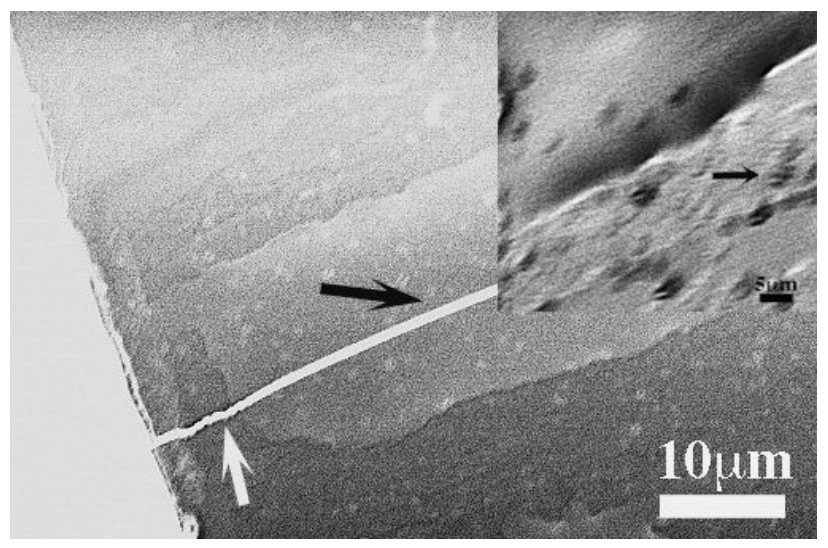

Fig. 6. SEM micrographs-of a fracture line (a) and details of the valley (b) of a wheel face of $\mathrm{Fe}_{40} \mathrm{Ni}_{38} \mathrm{Mo}_{4} \mathrm{~B}_{18}$ ribbon annealed at $750^{\circ} \mathrm{C}$ during $18 \mathrm{H}$ in vacuum

As a transport network, the hill are nodes or basins, and veins the lines that can be associated with, a conductance, a resistance, or a strain. The bead feature of the hill (see Fig. 3) is not modified by crystallization, and its hardness is very low. This latter aspect needs to be confirmed by further investigations. Thus, the ribbon shows a solidification of a melt, which, must be opposed to a melt's solidification in the case of crystallization from melt.

In conclusion, we propose a description of the microstructure of the two surfaces; free side surface (FSS) and wheel side surface (WSS) of an amorphous/glassy ribbon in terms similar to a leaf that are suitable to understand transport and mechanical properties of amorphous materials. Further investigations will relate this description with the specific high resistivity and tensile strength of amorphous materials.

\section{References}

1. T. Aboki, Thesis, University Pierre et Marie Curie (1989)

2. H.H. Libermann, R.E. Maxwell, R.W. Smashey, J.L. Walter, Met. Trans. 14, 1817 (1983)

3. J. Bigot, M. Harmelin, Thermo. Acta 121, 223 (1987)

4. E. Katifori, G.J. Szöllosi, M.O. Magnasco, Phys. Rev. Lett. 104, 048704 (2010)

5. F. Corson, Phys. Rev. Lett. 104, 048703 (2010)

6. P.S. Dodds, Phys. Rev. Lett. 104, 048702 (2010)

7. T.A.M. Aboki, F. Brisset, J.P. Souron, A. Dezellus, P. Plaindoux, Inter. 16, 615 (2008)

8. L.P. Hoang, P. Sacovy, J. Delaplace., J. Nucl. Mater. 114, 15 (1983)

9. T.A.M. Aboki, J.G.Gasser, unpublished results. 